\title{
Ticari Araç Koltuk Üretiminde Yerleşim ve Süreç Iyileştirilmesi
}

\section{Layout and Process Improvement in Commercial Vehicle Seats Manufacturing}

\author{
Hasan Tolga Alaf ${ }^{1 *}$, Tijen Över Özçelik ${ }^{2}$ \\ Geliş / Received: 18/06/2021 \\ Revize / Revised: 29/09/2021 \\ Kabul / Accepted: 01/10/2021
}

\section{ÖZ}

Bu çalışmada otomotiv koltuk üreticisi firmasının 2015 yllından başlayarak 2020 yılına kadar kapasite artı̧ talebini karşılamak amaciyla çeşitli kısıtlar çerçevesinde ürettiği aksiyonlar incelenmiş̧ir. Ele alınan konunun çözümüne yönelik uygulamalı bir proje çalışmasıdır.Çalışma kapsamında tam sırasında üretim, ürün kompleksitesi, fabrika yerleşimi, montaj hatları, hat dengeleme ve ergonomi gibi temel kavramların literatür karşlıkları incelenmiş ve öznel uygulama projesi konusu ile ilişkilendirilmiştir.Müşteri beklentisi analiz edilerek probleme çözüm üretecek şekilde çalışma aşamaları adım adım ortaya konmuştur. Yapılan araştırmada kapasite ve ürün çeşitliliğindeki artısa cevap verecek operasyonel yapının matematiksel modelleme zorluğu sektöre özel kısıtlar çerçevesinde ortaya konmuştur. Bu zorluk sebebiyle deneyime ve sezgiye dayalı sektöre özel çözümlerin önemi vurgulanmıştır.

Anahtar Kelimeler- Otomotiv, Yerleşim Planı, Proses, Montaj Hattı, Esnek İmalat

\begin{abstract}
In this study, the actions of the automotive seat manufacturer company within the framework of various constraints in order to meet the demand for capacity increase from 2015 to 2020 were examined. It is an applied project work aimed at solving the problem. Literature equivalents of basic concepts, such as production, product complexity, factory layout, assembly lines, line balancing, and ergonomics were examined and related to the subjective application project topic. After analysing the customer expectation, the working steps are laid out step by step in a way to respond to it. In the research, the mathematical modelling difficulty of the operational structure that will respond to the increase in capacity and product variety has been revealed within the framework of sector-specific constraints. Because of this difficulty, the importance of industry-specific solutions based on experience and intuition has been emphasized.
\end{abstract}

1*Sorumlu yazar iletişim: hasanalaf@gmail.com (https://orcid.org/0000-0003-4218-8542)

Endüstri Mühendisliği, Mühendislik Fakültesi, Sakarya Üniversitesi Esentepe Kampüsü, Sakarya, Türkiye

2İletişim: tover@sakarya.edu.tr (https://orcid.org/ 0000-0002-9614-8119)

Endüstri Mühendisliği, Mühendislik Fakültesi, Sakarya Üniversitesi Esentepe Kampüsü, Sakarya, Türkiye 


\section{GİRIŞ}

Uluslararası Motorlu Araç Üreticileri Organizasyonu (OICA) verilerine göre araç satışları son on yılda ciddi bir artış göstererek yüz milyon sınırına yaklaşmıştır [1]. Bu artışlara paralel olarak Tablo 1'de gösterildiği gibi ticari araç satışlarında da yükselme gözlenmektedir.

Global eğilime paralel şekilde, Otomobil Sanayi Derneği (OSD) verilerine göre 2019 yılında Türkiye'de 982.642'si binek otomobili olmak üzere 1.461.244 araç üretildi. Otomotiv toplam ihracatımız 31,2 milyon dolara ulaştı. Bu finansal değer otomotivin Türkiye ekonomisindeki önemini gözler önüne sermektedir. Yine OSD verilerine göre otomotiv, toplam ihracatımızın \%15'ini oluşturmaktadır ve son on beş yıldır en büyük ihracat sektörümüzdür. Üretilen araçların \%85 ihraç edilmektedir. GSYH'mizin \%3’ü bu sektörden kaynaklanmaktadır. Türkiye özellikle hafif ticari araç üretiminde Avrupa'nın en büyüğü haline gelmiştir ve dünyanın en büyük 14ncü otomotiv üreticisi konumundadır [2].

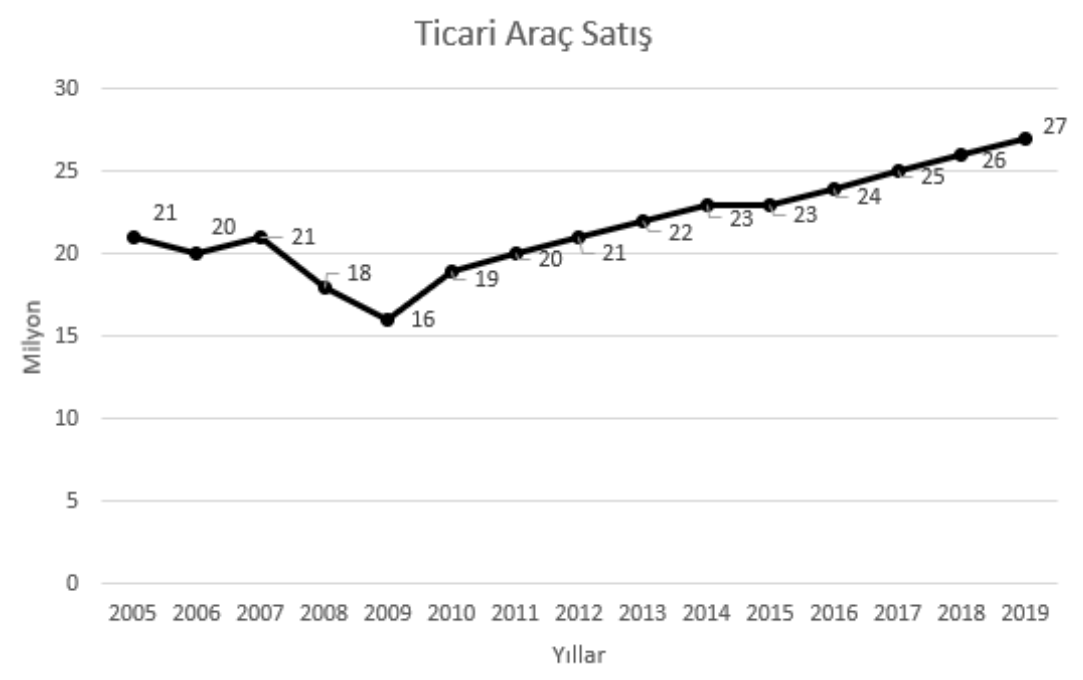

Şekil 1. Yıllara göre dünyada ticari araç satışı adedi [1]

$\mathrm{Bu}$ çalışma koltuk tedarikçisi firma ana sanayi müşterisinin 2015 - 2020 dönemindeki kapasite ve ürün çeşidindeki artış talebini operasyonel kısıtlar çerçevesinde çözmektedir. Çözüm incelenirken konu hem dünyada hem de pazarda değişkenlik, belirsizlik, karmaşıklık ve muğlaklık (VUCA) kavramı bağlamında ele alınmıştır.

\section{LITERATÜR ARAŞTIRMASI}

Otomotiv endüstrisinde gittikçe artan talebe yönelik olarak tedarik zincirinde kapasite planlaması ve sipariş çeşitliliği yönetimi matematiksel modellemesi zor bir problem haline gelmiştir. Bu problemin çözümüne yönelik olarak otomotiv endüstrisindeki çevik üretim stratejileri, sıralama ve planlama konusunda yeni zorlukları beraberinde getirmiş̧ir. Problemin zorluk derecesi, ürün çeşitliliği, zaman baskısı, talep artışı, tesis yerleşimi, kalite kriterleri ve maliyet gibi etkenlerle yükselmektedir [3]. Bu gerçeği Mc Kinsey \& Company otomotive yönelik olarak yapmış olduğu 2020 ve sonrasına işaret eden çalışmasında teyit etmekte, raporunda bulgularından ilkini ürün çeşitliliği ve maliyet baskısı olarak vermektedir [4].

Anılan etkenler, içinde bulunduğumuz dalgalanma, belirsizlik, karmaşıklık ve muğlaklık (VUCA) çağı bağlamında değerlendirilmelidir. Pandemiler, bölgesel savaşlar, terör, ekonomik buhranlar, hızla gelişen teknoloji, siyasi gerilimler gibi olaylar hemen hemen hayatın her yönünü etkilemektedir. Diğer yandan sektöre özel pazar ve müşteri tarafında da aynı belirsizlikler bulunmaktadır. Bu durum, hem kişisel hem de organizasyonel bazda çok yönlü düşünme, çeviklik, inovasyon, adaptasyon, esneklik ve iletişim becerilerinin gelişmesini zorunlu kılmaktadır. VUCA kavramının çerçevesi Şekil 2'de verilmiştir [5].

Kapasite ve ürün çeşitliliği artış talebi değerlendirilirken bilinmesi gereken temel kavramlar sırasıyla tam sırasında üretim (JIS), ürün kompleksitesi, fabrika yerleşimi, montaj hatları, hat dengeleme ve son olarak da hat ergonomisidir. 


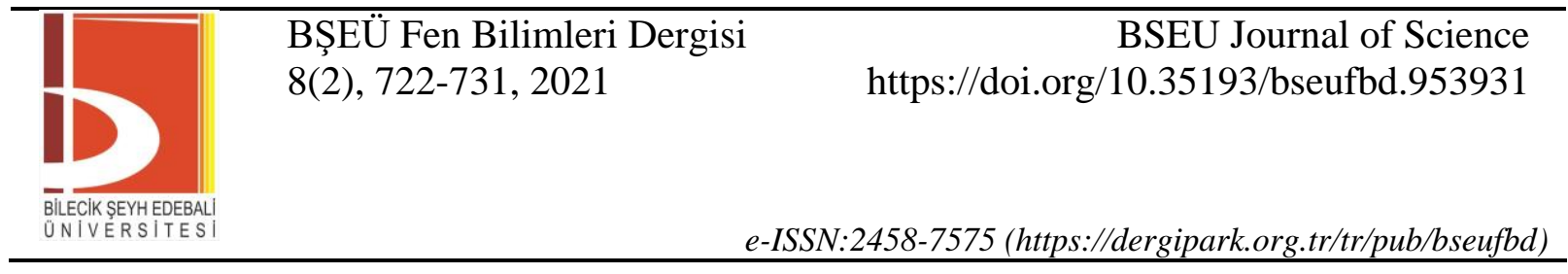

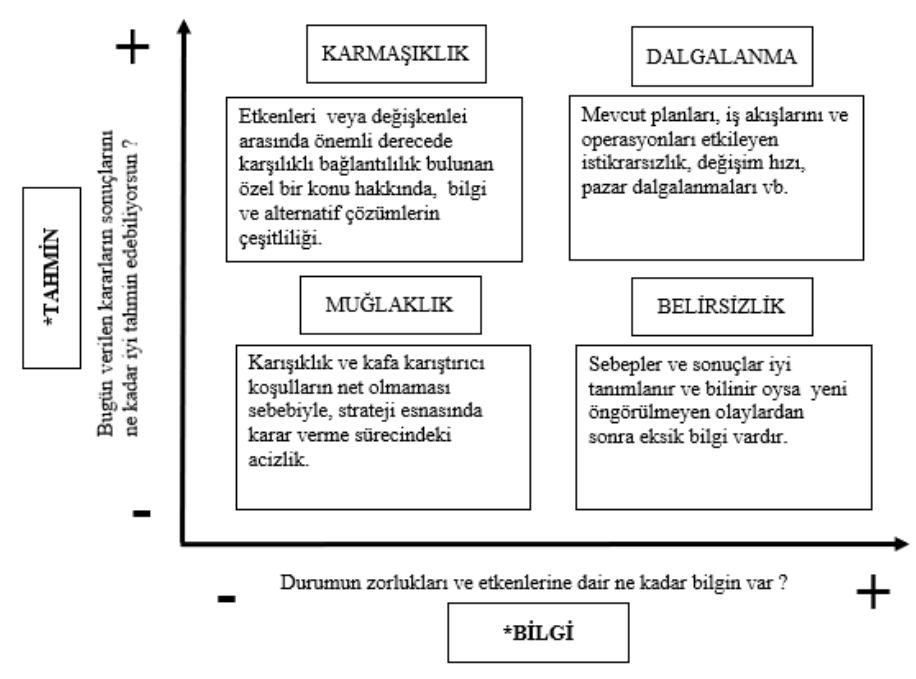

Şekil 2. VUCA kavramsal çerçevesi [5]

\section{A. Tam Zamanında Üretim (JIS)}

JIS üretim felsefesi, JIT üretim felsefesinin bir türevi olarak ele alınabilir. Otomotiv özelinde değişkenliği olan müşteri siparişlerine göre (EDI: Electronic Data Interchange) otomotiv ana sanayi fabrika üretimiyle, tedarikçi fabrika üretimleri arasında eşgüdümü sağlamayı amaçlar. Bu amaçla ara nakliye sürecini optimize eden tedarikçi parkları kavramı ortaya konulmuştur. Aynı yerleşke içerisinde tüm tedarikçilerin ana sanayiyle birlikte çalışması sağlanmış olur. JIT üretim felsefesinde tanımlanan israf noktaları hatalı parça üretimi, üretim fazlası, stok fazlası, gereksiz ve uygun olmayan işler, gereksiz hareketler, gereksiz nakliye ve bakım işleri, ölü zamanlar, müşteri beklentilerini karşılamayan ürün ve hizmetlerdir [6]. JIS üretim felsefesinde özellikle nakliye ve stok alanında kayıplar en aza indirilir ve odak olarak alınır. JIT ve JIS proseslerin görsel ifadesi Şekil 3'te verilmiştir [7].
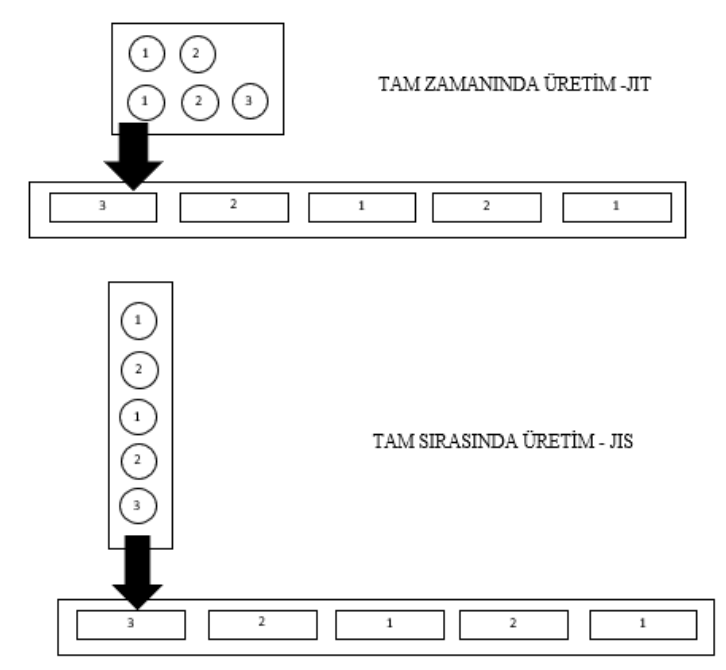

Şekil 3. JIT ve JIS üretim süreci [7]

\section{B. Ürün Kompleksitesi}

Üretim yapan tesislerde ürün çeşitliliği giderek zorlayıcı bir etken olmaktadır. Bunun ana sebeplerinden bir tanesi de müş̧teri talebinin değiş̧kenliği ve öznelliğidir. Diğer yandan ürün ömrü de pazarın beklentisiyle uyum içerisinde giderek kısalmakta ve yeni ürünlerin piyasaya sürülmesi gerekmektedir. Otomotiv sektörü bu ürün çeşitliliğinden lojistik özelinde çok etkilenmektedir. Sonuç olarak artan ürün kompleksitesi, daha karmaşık lojistik süreçlerini beraberinde getirmektedir. Öte yandan ürün esaslı kompleksiteyi yönetmek için belirlenmiş kapsayıcı 
bir performans göstergesi henüz tanıtılmış değildir. Ürün esaslı kompleksitenin temel etkenleri Tablo 1'de verilmiştir [8].

Tablo 1. Kompleksitenin temel etkenleri [8]

\begin{tabular}{|c|c|c|}
\hline Etken & Etken Tanımı & Etken Açıklaması \\
\hline 1 & Araç Modeli Sayısı & $\begin{array}{l}\text { Artan her araç modeli beraberinde artan parça } \\
\text { sayısını getirir. }\end{array}$ \\
\hline 2 & Parça Referans Sayısı & $\begin{array}{l}\text { Varyant parçalar ülke özgü üretimler, } \\
\text { opsiyonel ekipmanlar gibi sebeplerden } \\
\text { gerekebilir; her varyant parça artan alan } \\
\text { ihtiyacı doğurur dolayısıyla siralamalı } \\
\text { tedarik zinciri gerektirir. }\end{array}$ \\
\hline 3 & Platform Sayısı & $\begin{array}{l}\text { Platform stratejisi, modeller içindeki parça } \\
\text { ortaklığını arttırır. }\end{array}$ \\
\hline 4 & $\begin{array}{l}\text { Ortak Olmayan Parçaların Ortak Parçalara } \\
\text { Oranı }\end{array}$ & $\begin{array}{l}\text { Yüksek ortak parça oranı, tesisteki toplam } \\
\text { parça sayısını azaltır. }\end{array}$ \\
\hline 5 & Üretim Artışı Sayısı & $\begin{array}{l}\text { Tedarik süreçleri ayarlanmak zorundadır ve yeni } \\
\text { parçalar mevcut yapıya entegre edilmelidir. }\end{array}$ \\
\hline 6 & Ölen Araç Modeli Sayısı & Tedarik süreçleri ayarlanmak zorundadır. \\
\hline 7 & Ara Model Sayısı & $\begin{array}{l}\text { İlave ürün çeşitliliği ve değiştirilen parçalar entegre } \\
\text { edilmelidir. }\end{array}$ \\
\hline 8 & Üretimin Hacmi & $\begin{array}{l}\text { Yüksek üretim hacmi, yüksek tedarik hacmi } \\
\text { demektir. }\end{array}$ \\
\hline
\end{tabular}

\section{Fabrika Yerleşimi}

Tesis yerleşim problemi 1950'lerden bu yana üzerinde çalışılan bir konudur. Tesis yerleşim problemine yaklaşımda temel problemler, detay ve temsiliyet seviyesine karar verme, nesnel fonksiyon bileşenleri (malzeme elleçleme maliyeti, tekrar yerleşim maliyetleri, dolaşımdaki envanter, akış zamanları) ve malzeme akış karakteristikleridir (deterministik, stokastik, statik ya da dinamik). Statik malzeme akışında ürün çeşidi ve hacmi planlanan zaman dilimi içerisinde sabitken, dinamik malzeme akışında hem ürün çeşidi hem de hacmi değişkenlik göstermektedir. Deterministik malzeme akışında her ikisi de öncesinde tam anlamıyla bilinmektedir. Stokastik malzeme akışında ise öncesinde bu bilgilere sahip değilizdir. Konvansiyonel yerleşim tasarımları ürün, süreç, hücresel ve sabit ürün yerleşimleridir.

Geleneksel yerleşim planları günümüz üretim gerekliliklerini karşılamamaktadır. Örneğin esneklik ve yenidendüzenlenebilirlik. Üreticiler beraberinde getirdiği maliyet ve kayıplardan ötürü yerleşim planı değişimlerine sıcak bakmamaktadırlar.Geleneksel yerleşim planları benzer ürünlerin uzun zaman boyunca üretileceği şekilde tasarlanmışlardır. Proses yerleşim planları, uzun zaman, büyük süreç içi envanter ve verimsiz malzeme elleçleme gerektiren karmaşı ve dinamik üretim planları için uygun değildir. Benzer şekilde hücre yerleşim planlarında benzer gereklilikleri olan ürün aileleri için tasarlanmışlardır. Bu da talep dalgalanmaları ve yeni ürün tanıtımlarında verimsizlik getirmektedir. Literatürde ürün çeşitliliğinin ve talebin dalgalandığı dinamik üretim şartları için yapılmış pek az çalışma vardır ve yeni nesil yerleşim planlamalarına ihtiyacı ortaya koymaktadır [9].

\section{Montaj Hatlart}

Seri üretim yapan tesislerdeki üretim hatları akış hatları olarak tanımlanmaktadır. Bu hatlar ürün özelliklerine göre tasarlanırlar ve gerekli işlemlerin ardıllık ilkesine göre istasyonlarda yapılmasıyla faaliyet gösterirler. Sürekli olarak aynı ya da benzer ürünler hattan çıkar. Seri üretimin dört ana ilkesine göre tasarlanır ve işletilirler. İş akışı ilkesi, ikame parça ilkesi en az uzaklık ilkesi, iş yükü dağılımı -hat dengeleme ilkesi. İki tip üretim hattı sınıflandırılması yapılabilir. Transfer hatları ve montaj hatları. Otomotivde ağırlıklı olarak montaj hatları kullanılır [10].

Tablo 2'de verilen geleneksel iki hat tipinin de modern pazar ihtiyaçlarına cevap verecek şekilde karmaşık hatlara evrilmesi gerekliliği bulunmaktadır. Bu tür karmaşı hatlar Endüstri 4.0 şartlarını yerine getiren dijital 
dönüşüm uygulamalarıdır. Siber fiziksel sistemler (CPS) tarafından kontrol edilen bu karmaşık hatların şematik gösterimi Şekil 4’te verilmiştir [11].

Tablo 2. Kesikli seri üretim akış hatlarının açıklamalı sınıflandırılması [10]

\begin{tabular}{ccccc}
\hline \multicolumn{1}{c}{ Akış Hattı Tanımı } & Üretim Sayısı & Ürün Değişimi & Birimlerin Akışı \\
\hline Grup & Alt Grup & & & \\
Transfer Hattı & Tek Ürün & 1 & Yok & Düzenli \\
& Çok Ürün & $>1$ & Parti değişimi & Yığınlarda düzenli \\
Tek Ürün & 1 & Yok & Düzensiz $(*)$ \\
& Çok Ürün & $>1$ & Parti değişimi & Düzensiz $(*)$ \\
& Karışı ürün & $>1$ & Sürekli $(* *)$ & Düzensiz $(*)$ \\
\hline
\end{tabular}

(*) Değişken istasyon sürelerinden dolayı bu durum montaj hatlarının belirgin özelliğidir (**) Herhangi bir zamanda, hat üzerinde, birkaç ürün tipinin bir karışımı bulunur.

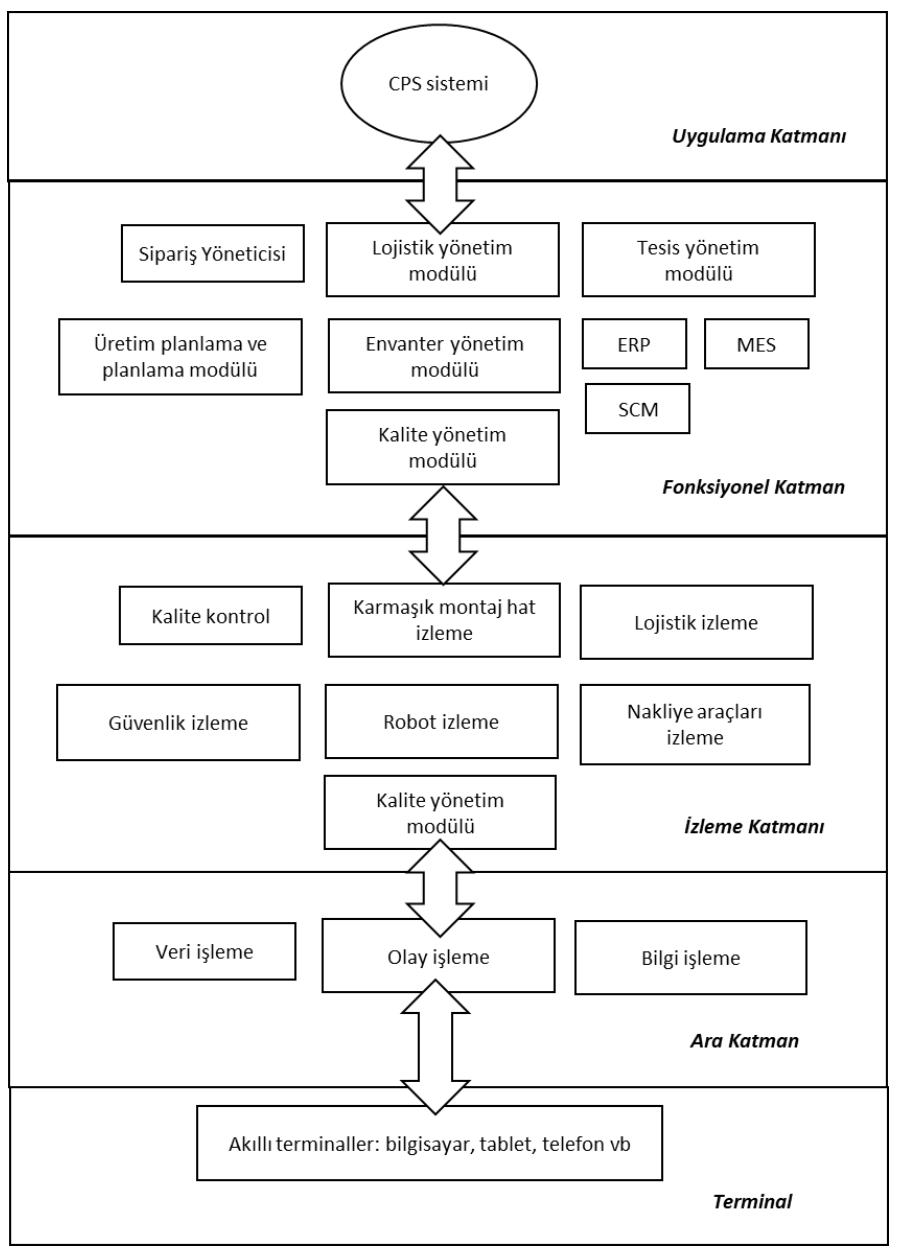

Şekil 4. CPS Yapısı [11]

Geleneksel hatlarda da yeni nesil montaj hatlarında da hat dengeleme dikkat edilmesi gereken önemli bir kavramdır. Montaj hattı dengelenmesinde dikkate alınacak kriterler malzeme akışının düzenli olmasıdır. İşçi ve 
makine kapasitesinin en üst seviyede kullanılması, kayıp sürelerin en aza indirilmesi, kayıp sürelerin istasyonlar arasında dengeli dağılımı, maliyet azaltılmasıdır. Hat dengelemenin amaçları her zaman birbiriyle örtüşmediğinden en uygun çözümün bulunması gerekir. Dengeleme işleminde maliyet etkisi olan iki etkenden ilki işgücü, ikincisi alan maliyeti ve yatırım gereksiniminden ötürü hat uzunluğudur [10].

\section{E. Hat Ergonomisi}

Gelişen teknoloji insan gücüne olan ihtiyacı ortadan kaldırmamıştır. Yoğun iş gücü gerektiren işlemlerde ergonomik olmayan çalışma ortamı ve çalışma duruşları iskelet kas sistemlerinde arızalara yol açmaktadır, ayrıca beraberinde iş verimliliği de düşmektedir. Saha çalışmaları insanı en çok etkileyen faktörlerin ağır kaldırma, tekrarlayan hareket, yanlış duruşlar, yüksek tempoda çalışma olduğunu ortaya koymuştur. Ergonomik çalışmalar aşağıda verilen noktaları dikkate alır:

- Ekipman ve makina tasarımlarında kullanıcı faktörünün dikkate alınması

- Çalışma ortam ve yöntem belirlenmesinde insan faktörünün dikkate alınması

- Çalışana yetenek ve potansiyelini ortaya çıkaracak imkânların verilmesi

- Çalışanın yaptığı işte anlam bulması ve motivasyonu

$\mathrm{Bu}$ şartlar altında salt bedensel zorlanma değil psikolojik zorlanma da bertaraf edilmiş olur. Doğru yapılmış bir ergonomi çalışması, iş sürelerinde iyileşmeye, strese bağlı kazalarda, devamsızlıkta, işgücü kayıplarında, kullanılan ekipmanın bozulması ve bakım gerekliliğinde azalmalara yol açar. Dolayısıyla da verimlilik, karlılık ve kalite olarak işletmeye katma değer sağlar [12].

\section{YÖNTEM}

Müşteri fabrikasında iki model ticari araç üretmektedir. Bu iki model için koltuklar, 6 farklı üretim hattında ve offline adı verilen hücre tipi yapılarda yürütülmektedir. İki projenin ön sıra koltukları aynı hatlarda üretilmektedir.

- Ön Sira Tekli Koltuk Hattı

- Ön Sıra Çiftli Koltuk Hattı

- Arka Sira Flamingo Koltuk Hattı (2 hat)

- Arka Sira M2 Koltuk Hatt1 üretilmektedir.

- Çoklu Koltuk Hattı. Bu hatta her iki proje için arka sıralarında kullanılan üçlü, dörtlü büyük koltuklar

Montaj hatları sıralı istasyon şeklinde yapılandırılmıştır ve parça beslemeleri hat arkasında bulunan süper marketlerden yapılmaktadır. Koltuk montajında kullanılan ana bileşenler, metal karkas, sünger, kılıf, plastik, kolçak, başlık, katlanır masa (FOT), emniyet parçaları, bağlantı elemanları, elektrik aksamı, bel destekleri, sensörlerdir. Bileşenler yurt içi ve yurt dışındaki tedarikçilerden toplanmaktadır.Montaj hatlarında 1. Proje için yayın zamanlaması $120 \mathrm{dk}$, 2. Proje için için yayın zamanlaması $140 \mathrm{dk}$ 'dır. Yayın zamanlaması araç montajında boya öncesi istasyona giriş zamanını ifade eder. Bu süreler içerisinde ilgili koltukların ürün ağacında bulunan bileşenlerinin toplanması, hat üzerinde bir araya getirilmesi, son kontrollerin yapılması, kaliteden onaylı bir şekilde doğru olarak sıralanarak araç fabrikasında koltuk taşıyan vagonlara yerleştirilmiş olması gerekmektedir. Koltukların uygun sırayla tam zamanında araç montaj hattına girmesi beklenir.Koltuk fabrikası genel olarak istisnai durumlar dışında bitmiş ürün stoku yapamamaktadır.Koltuk bileşenleri açısından yurtdışından gelen için en fazla bir haftalık stok bulunmaktadır, yerli tedarik parçaları için en fazla iki günlük stok bulunmaktadır. Avantajlarına karşın koltuk fabrikasında yüksek adetli ürün oranı müşteri talebine istinaden toplam üretimde $\% 5$ 'ten az yer tutmaktadır. Ürün çeşitliliği yüksek, o ürüne ait üretim adedi düşüktür.

İki projeye ait 26 farklı koltuk yerleşim kombinasyonu bulunmaktadır. Ürünün kompleksitesini şu parametreler belirlemektedir: kılıf tipi, kılıf rengi, ısıtıcı, HVAC modülü, soldan-sağdan direksiyon, emniyet kemer sensörü, kolçak, orta sehpa, bel desteği, hava yastı̆̆ı, karkas güçlenlendirme, yaslanma derecesi. Müşterinin kapasite artı̧̧ talebi Tablo 3’te verilmiştir. 


\begin{tabular}{|c|c|c|}
\hline & $\begin{array}{l}\text { BŞEÜ Fen Bilimleri Dergisi } \\
8(2), 722-731,2021\end{array}$ & $\begin{array}{r}\text { BSEU Journal of Science } \\
\text { https://doi.org/10.35193/bseufbd.953931 }\end{array}$ \\
\hline & & 2458-7575 (https://dergipark.org.tr/tr/pub/bseufbd) \\
\hline
\end{tabular}

Tablo 3. Müşteri kapasite artış talebinin yıllara göre dağılımı

\begin{tabular}{|c|c|c|c|c|c|}
\hline & \multirow{3}{*}{$\begin{array}{c}\text { Kurulu } \\
\text { Kapasite }\end{array}$} & 2015 & 2017 & 2018 & 2019 \\
\hline & & $\begin{array}{l}\text { Kapasite } \\
\text { Çalışması }\end{array}$ & $\begin{array}{l}\text { Kapasite } \\
\text { Çalış̧ması }\end{array}$ & $\begin{array}{l}\text { Kapasite } \\
\text { Çalış̧ması }\end{array}$ & $\begin{array}{l}\text { Kapasite } \\
\text { Çalış̧ması }\end{array}$ \\
\hline & & $\# 1$ & $\# 2$ & $\# 3$ & $\# 4$ \\
\hline 1. Proje & $165 \mathrm{~K}$ & $130 \mathrm{~K}$ & $180 \mathrm{~K}$ & $180 \mathrm{~K}$ & $187 \mathrm{~K}$ \\
\hline 2.Proje & $132 \mathrm{~K}$ & $110 \mathrm{~K}$ & $132 \mathrm{~K}$ & $140 \mathrm{~K}$ & $150 \mathrm{~K}$ \\
\hline Diğer Pazarlar & $9 \mathrm{~K}$ & $6 \mathrm{~K}$ & $9 \mathrm{~K}$ & $9 \mathrm{~K}$ & $9 \mathrm{~K}$ \\
\hline Toplam Araç /Yıl & $297 \mathrm{~K}$ & $240 \mathrm{~K}$ & $312 \mathrm{~K}$ & $320 \mathrm{~K}$ & $337 \mathrm{~K}$ \\
\hline
\end{tabular}

Talep iletildiğinde koltuk fabrikasında operasyonel durum şöyledir:

- 288 Çalışan

- 760 farklı tipte koltuk

- 1215 satın alma parçası

-1.Proje ikili vardiya, 2. Proje tek vardiya düzeninde çalışmaktadır

- $5452 \mathrm{~m}^{2}$ kapalı, $5988 \mathrm{~m}^{2}$ açık alan kullanılmaktadır.

JIS prensibinden dolayı montaj hatlarının tedarikçi parkı içerisinde bulunma zorunluluğu vardır. Tedarikçi parkında ilave alan talebi müşteri tarafından kendi kısıtları sebebiyle olumlu karşılanmamıştır. Bütün bu bilgiler 1şı̆̆ında müşteri 2015 yılından 2019 yllına kadar kendi araç üretim kapasitesini \%40 artırmayı planlamaktadır. Koltuk fabrikası sıralama yapması sebebiyle tedarikçi parkı dışında montaj yapamamaktadır. Tedarikçi parkı içinde ilave alan tahsis edilememektedir. Bu kısıtlar çerçevesinde üretimde herhangi bir kesintiye yol açmadan müş̧eri talebiyle paralel olarak koltuk üretim kapasitesini artırması gerekmektedir.

\section{BULGULAR}

Müşteri talebine yönelik koltuk fabrikası, aksiyon planını ilgili kapasite artış talebine spesifik aşamalar halinde çözümlemiştir.

\section{A. Kapasite Çalışması 1}

1. Proje iki vardiya düzeninden üçlü vardiya düzenine geçmiştir. Alınan bir dizi hat iyileştirme aksiyonlarıyla vardiyalık 1. Projeye ait arka sıra flamingo koltuk üretim kapasitesi 250'den 277'ye çıkarılmış, günlük koltuk kapasitesi 877 olmuştur. Eklenen vardiya sebebiyle 72 operatör alınmıştır.

Günlük talep arttığı için günlük envanter miktarı da artmıştır. Artış sebebiyle $1000 \mathrm{~m}^{2}$ alan ihtiyacı doğmuştur. Bu ihtiyacı karşılamak için yanal büyüme imkanı olmadığından, çözüm üretilerek fabrika içerisinde mezanin adı verilen ara kat yapılmıştır. Mezanin üzeri kılıf, sünger ve plastik stok alanı olarak kullanılmıştır. Mezanin yapılması ardından zemin katta bulunan montaj hattı operasyonlarındaki verimi artırmak ve ara taşıma işleminden kurtulmak için yer çekimi kuvvetinden yararlanarak yukarıdan aşağıya ray üzerinde hat beslemesi uygulaması devreye alınmıştır. Havadan yapılan sıralama işlemi sebebiyle kurulu proses değiştiğinden tekrar hat dengelemesi yapılmıştır.

Deri koltuk miktarı gelen yeni taleple arttığından fönleme operasyonu ihtiyacı da artmıştır. Artan bu ihtiyaç ergonomiyi olumsuz etkileyecektir. Bu sebeple ergonomiyi iyileştirmek için ilgili istasyona asansör mekanizması kurulmuş, çalışanın koltuğa göre pozisyon alması yerine koltuğun dikey hareketi sağlanmıştır.

Üretim hızının artması sebebiyle, ön sıra tekli ve ön sıra çiftli koltuk montaj hatlarının ortasına robot uygulaması yapılmış,vardiyada 2, toplamda 6 operatör kazanılmıştır. 


\section{B. Kapasite Çalışması 2}

1. Proje arka sıra flamingo koltuk kapasitesi 832 'den 943 'e yükselmiştir. Bu talebi karşılamak için mevcut ve atıl istasyonları olan 2. Projeye ait arka sıra M2 montaj hattı revize edilerek flamingo koltuk montaj hattı haline getirilmiştir. 2. Projenin arka sıra M2 koltuk ihtiyacını karşılamaya yönelik olarak esnek imalata imkan tanıyan daha küçük 12 istasyonlu Endüstri 4.0'a uygun modüler bir hat kurulumu tamamlanmıştır.

Operasyonel verimsizliklerin bertaraf edilmesi için ön sıra tekli koltuk sırt giydirme prosesi mezanin katına taşınarak, montaj hattına havadan besleme yapılmıştır.

\section{Kapasite Çalışması 3}

$\mathrm{Bu}$ aşamada kapasite artı̧̧ ağılıklı olarak ön sıra koltukları ilgilendirmektedir. Bu amaçla ön sıra tekli koltuk montaj hattında istasyon sayıs1 19'dan 22'ye yükseltilmiştir ve günlük kapasite 1356'dan 1482'ye çıkmıştır . Ön sıra çiftli koltuk montaj hattı istasyon sayısı 19'dan 21'e yükseltilmiştir ve günlük kapasite 904'ten 988'e çıkmıştır. Ön sıra tekli koltuk offline montaj ünitesi sayısı 6'dan 7'ye yükseltilmiştir.

\section{SONUÇLAR}

Literatür taramasının da teyit ettiği üzere otomotiv sektöründe değişken talep ve esnek üretim problemi, kısıtlar da dikkate alındığında matematiksel modellemesi henüz tamamlanmamış bir konudur. $\mathrm{Bu}$ tür bir modellemenin kompleks yapısı, uygulamada firmaları ister istemez tecrübe ve sezgiye dayalı, sektöre özgü çözümler üretmeye yöneltmektedir. Gelişen teknolojiyle birlikte özellikle yapay zeka uygulamaları bu zor problemde her geçen gün sektöre daha fazla katkı sağlayacak ve optimizasyon firsatlarının daha etkin değerlendirilmesini sağlayacaktır.

Proje kapsamında firma, talep edilen kapasiteye ulaşmak ve kısıtları aşmak için yerleşim planı optimizasyonu, hat dengeleme, $5 \mathrm{~S}$, proses iyileştirme faaliyetleri gibi yatırım maliyetleri görece düşük uygulamaya yönelik çözüm teknikleri uygulamıştır. Bu tür uygulamaların işçilik maliyetlerinin görece düşük olduğu, yüksek yatırım imkânının olmadığı durumlarda yalın üretim teknikleri kullanılarak verimlilik, israf, iş sağlığı ve güvenliği, esneklik gibi konularda önemli iyileşmeler sağladığı literatürde bulunmaktadır ve bu çalışmanın sonuçlarıyla uyumludur [13].

İyileştirme faaliyetlerinin yanı sıra, robot kullanımı, modüler montaj hatları gibi Endüstri 4.0. gerekliliklerini de yerine getirerek hetorejen bir aksiyon planı izlenmiştir.

$\mathrm{Bu}$ aksiyon planı, üretim endüstrisindeki geleneksel üretim hatlarının yerini alan çevik montaj hatları eğilimiyle uyum içerisindedir. Mevcut otomotiv pazarının eğilimi daha fazla çeşitli ürünün, daha az hacimle birden fazla lokasyonda üretilmesini gerektirmektedir. Klasik montaj bantları her zaman ihtiyaca cevap vermemektedir zira çevrim süresi dengeleme problemi güçleşmektedir. Buna karşılık çevik montaj sistemleri, bahsedilen problemlere alternatif çözümler önermektedir [14].

Geriye dönük olarak aksiyon planının fabrika operasyonları üzerindeki etkisi temel performans göstergeleri üzerinden Tablo 4'te verilmiştir.

Benzer şekilde planlanan ve gerçekleşen üretim adetleri Şekil 5 'te verilmiştir. Küresel otomotiv pazarıyla uyumlu olarak üretim adetleri artış eğilimindedir. 2016 yılında kapasite artışı planlanmamıştır. Sonuç olarak firma proje uygulamasıyla müşteri beklentisini karşılayarak kapasite artışlarını desteklemiştir.

Tablo 4. 2015-2019 Performans göstergeleri üzerinden karşılaştırma tablosu

\begin{tabular}{lcccc} 
& & $\mathbf{2 0 1 5}$ & $\mathbf{2 0 1 9}$ & \% Değişim \\
\hline İnsan Kaynağı & Toplam Kişi & 288 & 476 & $65 \%$ \\
Ürün Çeşitliliği & Koltuk Tipi & 760 & 1240 & $63 \%$ \\
Satınalma Parça Sayısı & - & 1215 & 3086 & $154 \%$ \\
Çalışma Düzeni Vardiya & V362 & 2 & 3 & - \\
& V363 & 1 & 2 & - \\
Yerleşim Alanı $\left(\mathbf{m}^{2}\right)$ & Açık & 5988 & 5988 & $0 \%$ \\
& Kapalı & 5452 & 8552 & $57 \%$ \\
\hline
\end{tabular}




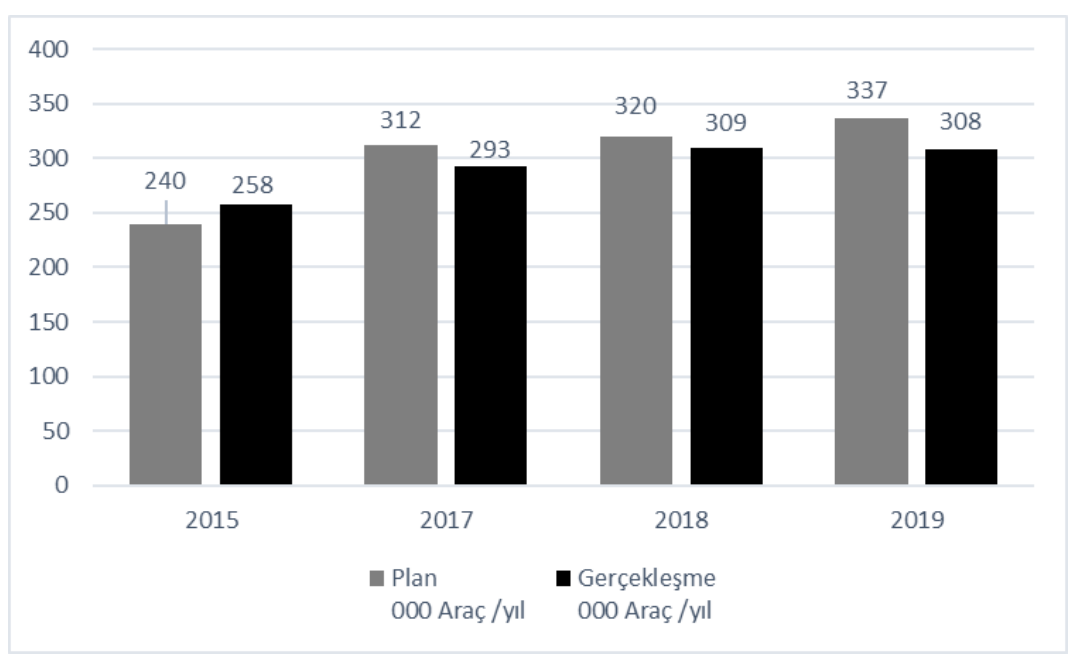

Şekil 5. 2015-2019 yılları arasında araç üretim plan ve gerçekleşme grafiği

\section{KAYNAKLAR}

[1] Uluslararası Motorlu Araç İmalatçıları Örgütü OICA. (2021). 2005-2019 Sales Statistics. https://www.oica.net/category/sales-statistics/. (Erişim Tarihi: 22/2/2021).

[2] Otomotiv Sanayi Derneği OSD. (2021). Aralı 2019 Otomotiv Sonuçları. http://www.osd.org.tr/haberler/aralik-2019-otomotiv-sonuclari-aciklandi/. (Erişim Tarihi: 22/2/2021).

[3] Fritzsche, A. (2018). Implications of agile manufacturing in the automotive industry for order management in the factories - evidence from the practitioner's perspective. 51st CIRP Conference on Manufacturing Systems, Procedia CIRP 72 369-374.

[4] McKinsey \& Company. (2020). The road to 2020 and beyond : What's driving the Global automotive industry? . Advanced Industries.

[5] Döner, E. (2020). "Vuca" faktörlerinin ürün inovasyon performansına olan etkilerinin incelenmesi. Yüksek Lisans Tezi, Adana Alparslan Türkeş Bilim ve Teknoloji Üniversitesi, Sosyal Bilimler Enstitüsü, Adana.

[6] Küçükçakıroğlu, M. (2000). Toyota üretim sisteminin gerçekleri. Yüksek Lisans Tezi, Çanakkale 18 Mart Üniversitesi, Sosyal Bilimler Enstitüsü, Çanakkale.

[7] Sarıkaya, K. (2019). JIT (Just-In-Time) Yaklaşımından JIS (Just-In-Sequence) Yaklaşımına Geçiş ve JIS'in Otomobil Endüstrisinde Modellenmesi. Koc. Üni. Fen Bil. Der., 2(2), 74-82.

[8] Feldhütter, V. Steck, C. Hawer, S. \& Ten Hompel, M. (2017) Impacts of product-driven complexity on the succes of logistics in the automotive sector. 10th CIRP Conference on Intelligent Computation in Manufacturing Engineering-CIRP ICME'16. Procedia CIRP 62, 129 - 134.

[9] Efeoğlu, B. (2016). Impact of demand uncertainty on facility layouts: distributed versus dynamic facility layouts. Yüksek Lisans Tezi, Ortadoğu Teknik Üniversitesi, Fen Bilimleri Enstitüsü, Ankara.

[10] Baskak, M. (1998). Çok modelli/ürünlü montaj hatlarının dengelenmesi için yeni bir model ve çözüm yöntemi. Doktora Tezi, İstanbul Teknik Üniversitesi, Fen Bilimleri Enstitüsü, İstanbul.

[11] Gong, L. Zou, B. \& Kan, Z. (2019). Modelling and optimization for automotive mixed assembly line in industry 4.0. Hindawi Journal of Control Science and Engineering, Article ID 3105267.

[12] Al, K. (2020). Otobüs fabrikasında ergonomik koşul değerlendirmesi. Yüksek Lisans Tezi, Marmara Üniversitesi, Fen Bilimleri Enstitüsü, İstanbul.

[13] Dias, P., Silva, F. J. G., Campilho, R. D. S. G., Ferreira, L. P., \& Santos, T. (2019). Analysis and Improvement of an Assembly Line in the Automotive Industry. 29th International Conference on Flexible Automation and Intelligent Manufacturing (FAIM2019), June 24-28, 2019, Limerick, Ireland. Procedia Manufacturing 38, 1444-1452. 


\begin{tabular}{|c|c|c|}
\hline & $\begin{array}{l}\text { BŞEÜ Fen Bilimleri Dergisi } \\
8(2), 722-731,2021\end{array}$ & $\begin{array}{r}\text { BSEU Journal of Science } \\
\text { https://doi.org/10.35193/bseufbd.953931 }\end{array}$ \\
\hline VER & & 2458-7575 (https://dergipark.org.tr/tr/pub/bseufbd) \\
\hline
\end{tabular}

[14] Burggräf, P., Dannapfel, M., Adlon, T., Kahmann, H., Schukat, E., \& Keens, J. (2020). Capability- based assembly design : An approach for planning an agile assembly system in automotive industry. 53rd CIRP Conference on Manufacturing Systems Procedia CIRP 93,1206-1211. 